This manuscript presents a review of the literature about nephrotoxicity of platinum derivatives, which are commonly used in paediatric oncology, such as cisplatin and carboplatin. It shows the incidence, pathomechanisms, risk factors, type and clinical features of the disorders. It presents differences in nephrotoxic effects of particular drugs, and describes possibilities of early detection and monitoring of clinical course and therapy. It emphasises the role of nephroprotective treatment. Hypomagnesaemia and decreased glomerular filtration rate (GFR) are the most common clinical manifestations of cisplatin and carboplatin nephrotoxicity. The assessment of kidney function during active antineoplastic treatment and after termination of the therapy is one of the key diagnostic elements permitting the prompt diagnosis of the side-effects of the therapy. The awareness of the risk factors predisposing to drug-induced nephrotoxicity influences its incidence and permits the application of suitable procedures aimed at kidney protection.

Key words: neoplasms of childhood, antineoplastic treatment, nephrotoxicity, platinum derivatives.

\section{Nephrotoxicity of platinum derivatives in children - a review of the literature}

\author{
Joanna Stefanowicz'1, Radosław Owczuk², Ewa lżycka-Świeszewska ${ }^{3}$, \\ Katarzyna Rückemann-Dziurdzińska ${ }^{4}$, Anna Balcerska ${ }^{1}$
}

\author{
1Department of Paediatric, Haematology, Oncology and Endocrinology, Medical \\ University of Gdansk \\ 2Department of Anaesthesiology and Intensive Therapy, Medical University of Gdansk \\ ${ }^{3}$ Department of Pathomorphology, Medical University of Gdansk \\ ${ }^{4}$ Department of Pathophysiology, Medical University of Gdansk
}

\section{Introduction}

Cancer and antineoplastic treatment are interrelated with the risk of injuring various tissues and organs, kidneys included. Nephrotoxicity is the major side-effect of numerous antineoplastic agents used in paediatric oncology. Chemotherapy may cause direct damage to various structures of the kidney (glomeruli, tubules, vessels) or indirect injury resulting from hypoperfusion, haemolytic-uraemic syndrome and tumour lysis syndrome [1]. More to the point, drug interactions may increase the serum concentrations of antineoplastic agents and thus intensify their nephrotoxicity through reductions in the rates of metabolic processes in the liver or reductions in renal clearance. The severity of the clinical course in kidney impairment consequent to cytostatics may range from subclinical dysfunction to life-threatening conditions. The signs and symptoms of nephrotoxicity depend on the site and the degree of kidney damage. Nephrotoxicity may present as an acute kidney injury, slowly progressing chronic renal disease or dysfunction of the renal tubules. These processes may or may not be reversible [2].

The common concept of kidney function, above all, refers to the filtration activity of the kidney. The activity is assessed using the estimated glomerular filtration rate (eGFR), which, in clinical practice, can be evaluated in a number of ways. However, one should bear in mind that glomerular filtration is just one of the functions executed by the kidneys. Additionally, the processes of tubular reabsorption and secretion exhibit dysfunction as a result of the damage to the renal tubule epithelium. The most severe clinical manifestation of the dysfunction of renal tubules is Fanconi syndrome, characterised by aminoaciduria, renal glycosuria and renal loss of phosphates, bicarbonates and potassium, with the consequent hypophosphataemia and hypophosphataemic rickets, proximal renal tubular acidosis (PRTA) and hypokalaemia [3-5].

For years the issue of monitoring nephrotoxicity, particularly late-onset, has been controversial. It remains inconclusive how often and which parameters should be assessed in long-term cancer survivors. Numerous clinical studies published worldwide differ not only in the choice of parameters but also in the analysed groups of patients, which are considerably heterogeneous. These differences cause considerable difficulty in comparing the obtained results.

Among cytotoxic agents, cisplatin (CDDP), carboplatin (CBDCA), ifosfamide (IFO), cyclophosphamide (CTX) and methotrexate (MTX) have known nephrotoxic activity [1].

In paediatric oncology the alkylating agents CDDP and CBDCA are the two most commonly used platinum derivatives. One of the most important sideeffects of their use is kidney damage.

Kidney susceptibility to platinum derivatives probably results from the role played by the kidneys as the major excretory organ for platinum. Kidneys accumulate more CDDP than any other organ, which can lead to necrosis of 
the terminal section of the proximal tubule and apoptosis of the distal nephron [6].

\section{Cisplatin}

The mechanism of cisplatin nephrotoxicity

Cisplatin administration and exposure to kidney cells, especially the proximal tubule, are associated with the activation of involving multifactorial and multidimensional processes comprising the activation of signal transduction pathways, leading to the damage and cell death of the renal tubule epithelium, the activation of inflammatory reactions, and vascular and ischaemic injury to the kidney. Kidney impairment results from the dysfunction of transporting networks, apoptosis or mitochondrial damage. Cisplatin binds extensively to DNA, damaging the double-stranded DNA and producing genotoxic stress that eventually triggers apoptosis of the renal tubule cells [7]. Studying an animal (rat) model has provided evidence that proximal tubules (S3 section) are the main sites of injury, which becomes overt three days after the administration of the drug. The morphological changes predominantly involve the terminal section of the proximal tubules. They take the form of focal damage of the brush border, cellular oedema, condensation of the nuclear chromatin, focal necrosis, altered number and shape of the lysosomes and mitochondrial vacuolisation [8]. On day five, changes in the terminal part of the proximal section become prevalent. Here, they take the form of tubular necrosis, leading to atrophy of the nephrons together with intratubular disintegration. A partial regeneration of the terminal part is observed on day seven. It manifests by the enlargement of the lumen of the tubules, which become lined with sliding epithelium. Additionally, the morphological changes are observed in the renal distal and collecting tubules. Even though morphological features of the tubular damage are well described and generally accepted, the mechanism of their formation remains unclear. Cisplatin may disturb the transport of organic cations. Human organic cation transporter 2 (hOCT2) is the transporter critical for cisplatin nephrotoxicity in isolated human proximal tubules. Organic cations such us cimetidine and verapamil (inhibitors of OCT2) protect the cells from the nephrotoxicity of CDDP $[9,10]$. Cisplatin, after entering the cell, may react with various reactive groups and, after activation, interacts with numerous particles, often glutathione. Cisplatin nephrotoxicity depends on metabolic activity and, above all, on its influence on $\gamma$-glutamyl transpeptidase and cysteine-S-conjugate $\beta$-1-hydrolase. The metabolic pathways of the aforementioned enzymes generate the more toxic derivatives of CDDP in the cells of the renal tubules, i.e., thiol and haloalkanes [10]. Cisplatin concentration in the renal tubular epithelium is five times higher than the serum concentration [11]. The tubular cells are exposed to CDDP during its secretion into the urine. In individuals with a normal renal filtration rate, a maximal CDDP level is observed three hours after drug administration. Necrosis may be the direct effect of toxic damage or may be a secondary event after apoptosis.

The exposure of the renal tubule cells to CDDP particles activates signal transduction pathways involving reactive oxygen species, mitogen-activated protein kinase, p53 and the cytoprotective p21, and promotes the death of the renal tubule epithelial cells. Cisplatin induces TNF- $\alpha$ production in the renal tubular cells, which triggers a robust inflammatory reaction and, in consequence, intensifies the impairment of the renal tubules and contributes to their death. Cisplatin may also interfere with renal blood perfusion, leading to ischaemic death of the tubular cells and, consequently, to decreased GFR and the development of acute renal insufficiency [12]. The death of the renal tubule cells through apoptosis and necrosis is the common basic manifestation of CDDP nephrotoxicity observed in histopathological examinations. Apoptosis resulting from CDDP exposure may be induced through the activation of the intrinsic (mitochondrial) pathway or, less commonly, through the activation of the extrinsic pathway based on death receptors (Fas, TNF- $\alpha$ receptors 1 and 2). The latter is activated by ligand (e.g., CDDP) binding, damage to the endoplasmic reticulum causing the activation of caspase 12 , and activation of the caspase-independent pathway. Previous studies have shown that the production of TNF- $\alpha$ by renal parenchymal cells, rather than by bone marrow-derived infiltrating immune cells, is responsible for CDDP-induced nephrotoxicity [13]. Additionally, endoplasmic reticular stress may trigger the activation of the pathways leading to apoptosis that is dependent on or independent of caspases [12]

\section{Risk factors of cisplatin nephrotoxicity}

Risk factors that increase kidney impairment after CDDP administration include previous or concomitant renal diseases, solitary kidney (nephrectomy), combined anticancer treatment with IFO and MTX, concurrent treatment with other nephrotoxic agents such as aminoglycosides and amphotericin $B$, the cumulative dose of CDDP ( $\left.\geq 200 \mathrm{mg} / \mathrm{m}^{2}\right)$, radiation impacting the kidney (renal radiation dose $\geq 15 \mathrm{~Gy}$ ), diabetes mellitus, hypertension, dehydration and hypoalbuminaemia $[2,14,15]$.

\section{Clinical aspects of cisplatin nephrotoxicity}

The nephrotoxic activity of CDDP may manifest itself as an acute kidney injury and chronic kidney disease. Kidney damage may affect glomeruli, proximal, distal and collecting tubules. Clinical manifestations of CDDP nephrotoicity include decreased GFR, electrolyte disturbances, polyuria and, infrequently, the renal salt-wasting syndrome [1]. Hypomagnesaemia and decreased GFR are the most common clinical manifestations of CDDP nephrotoxicity [2]. The grading of CDDP nephrotoxicity first proposed by Skinner in 1998 is widely used in clinical practice [14]. The scale is based on GFR and serum magnesium concentration (Table 1).

Hypomagnesaemia is present in almost $90 \%$ of patients treated with CDDP. It can be detected at only three months from the beginning of therapy, after reaching a cumulative dose exceeding $300 \mathrm{mg} / \mathrm{m}^{2}$ [16]. The disturbances in magnesium homeostasis related to CDDP treatment probably result from direct damage of the proximal and distal renal tubules [16]. Clinical and experimental studies have shown that CDDP interferes with magnesium transport, predominantly in the distal tubules [17-19]. Hypomagnesaemia 
Table 1. Grading of cisplatin (CDDP) nephrotoxicity in children [14]

\begin{tabular}{|c|c|c|c|}
\hline $\begin{array}{l}\text { Nephrotoxicity } \\
\text { grade }\end{array}$ & GFR & $\mathrm{Mg}<2$ years & $M g \geq 2$ years \\
\hline 0 & $\geq 90$ & 0.75 & 0.70 \\
\hline 1 & $60-89$ & $0.60-0.74$ & $0.55-0.69$ \\
\hline 2 & $40-59$ & $0.50-0.59$ & $0.45-0.54$ \\
\hline 3 & 20-39 & $\begin{array}{l}\text { no symptoms, } \\
\text { but } 0.40-0.49\end{array}$ & $\begin{array}{l}\text { no symptoms, } \\
\text { but } 0.35-0.44\end{array}$ \\
\hline 4 & $<20$ & $\begin{array}{c}\text { tetany or } \\
\text { convulsion }<0.40\end{array}$ & $\begin{array}{c}\text { tetany or } \\
\text { convulsion }<0.35\end{array}$ \\
\hline
\end{tabular}

Total score (Ns) (sum of GFR $+\mathrm{Mg}$ )

0 no nephrotoxicity

mild nephrotoxicity

2-3 moderate nephrotoxicity

$\geq 4$ severe nephrotoxicity

GFR - glomerular filtration rate ( $\left.\mathrm{ml} \mathrm{min-1} 1.73 \mathrm{~m}^{-2}\right)$; $\mathrm{Mg}$-serum magnesium concentration (mmol 1-1). Tetany is defined by clinical symptoms/signs (carpopedal spasm. Chvostek's sign, Trousseau's sign) with biochemistry (mode rate or severe hypomagnesaemia $<0.60$ at $<2$ years of age, $<0.55$ at $\geq 2$ years). Hypocalcaemia may also cause tetany. If hypomagnesaemia and hypocalca emia co-exist in the presence of tetany, assume that hypomagnesaemia is the primary cause unless there are good reasons not to do so, and grade appropriately. A score of 4 in an individual aspect of grading (e.g., GFR) constitutes severe toxicity in that aspect.

From Skinner R, Pearson ADJ, English MW, Price L, Wyllie RA, Coulthard MG, Craft AW. Cisplatin dose rate as a risk factor for nephrotoxicity in children. Br J Cancer 1998, 77(10), 1677-82 [14], with permission

caused by CDDP administration may persist for a few years after the end of therapy [20-23] and, in $1 / 3$ to $2 / 3$ children, may become permanent [21, 24].

Hypocalcaemia is another common electrolyte disturbance related to CDDP treatment. It may be caused by various mechanisms, but even the CDDP-induced hypomagnesaemia itself may lead to hypocalcaemia. Hypocalcaemia resulting from hypomagnesaemia is the consequence of the inhibition of parathyroid hormone (PTH) secretion and reduced tissue sensitivity to $\mathrm{PTH}$, as well as a direct effect of low serum magnesium concentration on calcium release from the bones. In addition, CDDP directly impairs the renal tubular cells, which are responsible for calcium reabsorption, leading to increased calcium loss in the urine. CDDPrelated hypocalcaemia is resistant to equalisation with only calcium supplementation. The mechanism of hypocalcaemia secondary to hypomagnesaemia implies that normalisation of the calcium level may be achieved only through simultaneous magnesium and calcium substitution [20]. In addition to hypomagnesaemia and hypocalcaemia, patients may also present with hypokalaemia [25] and, very rarely, hyponatraemia (renal salt-wasting syndrome) [26, 27].

Renal impairment is the main side-effect leading to CDDP dose limitation. Therapeutic protocols recommend a 50\% dose reduction if GFR drops under $60 \mathrm{ml} / \mathrm{min} / 1.73 \mathrm{~m}^{2}$. During antineoplastic treatment, it is mandatory to monitor the principal marker of the filtration activity of the kidney, i.e., GFR. GFR can be assessed using isotope methods (the gold standard for GFR assessment) or by the application of the Schwartz formula. Womer et al. reported a considerable inter-individual range of clinical manifestations of nephrotoxicity caused by CDDP therapy. They showed that after the administration of a $100 \mathrm{mg} / \mathrm{m}^{2}$ dose of CDDP, eGFR decreases, on average, by $8 \%$ [28]. The magnitude of GFR decrease is directly correlated with the peak platinum concentration in serum and/or urine and with the duration of CDDP infusion [29]. Cases of acute renal failure caused by CDDP have been reported previously [30]. Approximately $30 \%$ of patients undergoing CDDP treatment present signs of renal glomerulus dysfunction at the end of the therapy [31]. It remains the subject of intense discussion whether the observed decrease in GFR is reversible [31, 32]. Pietilä et al. published results of a study on a group of patients who had undergone antineoplastic therapy for a CNS tumour using protocols containing CDDP. After the end of the therapy, the patients were found to have significantly higher arterial blood pressure (15.4\%), especially those who had received brain radiotherapy (highest risk of arterial hypertension), had lower GFR or had hypomagnesaemia. The dysfunction in glomerular filtration was, in a majority of cases, persistent, but it generally did not present signs of progression in long-term observation [31]. In contrast, in the report published by Skinner et al., after a year of clinical observation, renal filtration activity radically improved: the mean GFR (corrected for body surface areast, BSA) was significantly higher than the GFR value measured at the moment of the termination of antineoplastic therapy (92 $\pm 10 \mathrm{ml} / \mathrm{min} / 1.73 \mathrm{~m}^{2} \mathrm{BSA}$ ) [14]. Similar observations were published by Brock and Gomez Campdera [21, 33]. Brock reported that $92 \%$ of children who had reduced GFR at the end of CDDP therapy, after a median of 2.5 years (range 1.5 7.0 years), presented at least some improvement in renal filtration activity (median GFR increase $22 \mathrm{ml} / \mathrm{min} / 1.73 \mathrm{~m}^{2}$ BSA), while $8 \%$ presented signs of chronic renal disease [21].

\section{Cytoprotective therapy to prevent the nephrotoxicity of platinum derivatives}

Intensive hydration simultaneous to CDDP administration, osmotic diffusion, magnesium supplementation, increasing duration of infusion and dividing the dose of CDDP within the cycle all decrease the nephrotoxicity of this cytostatic agent [25]. Hydration and intravenous mannitol administration reduce the incidence of CDDP nephrotoxicity by decreasing the exposure of the renal tubular cells to the drug [34]. Cisplatin is less nephrotoxic when administered in a long infusion compared to a bolus [29]. This results from the fact that endogenous sulphydryls present in renal tubules neutralise CDDP at lower concentrations but are less efficient at higher concentrations achieved by a CDDP bolus. Experimental studies on a rat model provided evidence that the accumulation and cytotoxic effects of CDDP on renal glomeruli and tubules depend on urine osmolarity. Low urine osmolarity enhances the accumulation and cytotoxicity of CDDP, while iso- and hyperosmolar urine have protective effects. These findings legitimise the strategy of the simultaneous intravenous infusion of osmotically active substances such as mannitol along with intensive hydration with $0.9 \mathrm{~g} / \mathrm{l} \mathrm{NaCl}$ saline and the use of $3 \mathrm{~g} / \mathrm{l}$ $\mathrm{NaCl}$ as a CDDP carrier [35, 36].

More to the point, hope has been placed in amifostine (Ethyol) application for reducing CDDP nephrotoxicity. The 
main mechanism of its protective action is the removal of free radicals [37]. Additionally, amifostine breaks the binding of CDDP to DNA, binds metabolites of cytotoxic agents, reduces apoptosis and activates tumour-suppressor gene p53. A limited amount of evidence suggests that amifostine might decrease hypomagnesaemia [32]. Regrettably, the studies assessing amifostine efficacy in paediatric populations show that it has only slight nephroprotective activity or even none at all [38, 39].

$\mathrm{N}$-acetylcysteine (NAC) is another agent considered to be CDDP-nephroprotective [40-42]. NAC inhibits apoptosis caused by CDDP by interfering with caspase signalling [43]. In clinical practice, NAC is administered intravenously as protection against CDDP and paracetamol toxicity in a phase II clinical trial currently underway to assess the treatment strategies for recurrent and resistant liver cancers (hepatoblastoma and hepatocellular carcinoma) [44]. Bassinger and Jones reported $\mathrm{D}$-methionine as a protection against CDDP nephrotoxicity [45]. Some other antioxidants, such as selenium, vitamin $C$ and $E$, and aminoguanidine, are believed to play a renoprotective role [46].

A liposomal formulation of CDDP, lipoplatin, has been intensely studied over the recent years. It is regarded as equally effective but much less nephrotoxic which has been confirmed in animal studies as well as in clinical trials in adult patients with advanced pancreatic cancer, non-small cell lung carcinoma, head and neck neoplasm and metastatic breast cancer $[47,48]$.

\section{Carboplatin}

\section{The mechanism of carboplatin nephrotoxicity}

After intravenous administration, most CBDCA is bound to plasma proteins, and only the free platinum causes cytotoxicity. Almost $90 \%$ of the administered dose is filtered through the kidneys [20]. Moreover, contrary to CDDP, CBDCA is not transformed into toxic metabolic compounds in renal tubule cells [10]. It is presumed that CBDCA is less nephrotoxic than CDDP because it is less reactive with the proteins of the renal tubules $[20,49]$.

\section{Risk factors of carboplatin nephrotoxicity}

Among the known CBDCA risk factors are the treatment of children who are older [50], single kidney, diabetes mellitus, hypertension [2], the cumulative dose of CBDCA [50] and simultaneous treatment with IFO and other nephrotoxins [2, 51]. Paradoxically, the risk of kidney insufficiency and renal tubulopathy development is higher in the case of CBDCA/IFO therapy than with CDDP/IFO therapy $[32,51]$.

\section{Clinical characteristics of carboplatin nephrotoxicity}

The nephrotoxic activity of CBDCA is, above all, characterised by decreased GFR and hypomagnesaemia. Acute renal failure after CBDCA has been reported in a few occasional cases [50-53]. In most of the clinical studies on CBDCA treatment in children, GFR values are reported to be within the norm or only slightly decreased [54]. Hypomagnesaemia is a rare finding [50, 55-57].

\section{Cytoprotective therapy to prevent carboplatin nephrotoxicity}

The administration of an exact, set dose of a cytostatic agent is the crucial factor that prevents the development of myelosuppression and nephrotoxicity. The major marker limiting the dose of CBDCA is the GFR value. The set dose of the cytostatic agent is calculated according to the formula proposed by Calvert et al., which takes into account the value of GFR and the area under the plasma concentration time curve $(A \cup C)$ : dose $[\mathrm{mg}]=$ target $A \cup C(\mathrm{mg} / \mathrm{ml} / \mathrm{min}) \times(G F R$ $(\mathrm{ml} / \mathrm{min})+25)$ [58]. Bearing in mind the atypical pharmacokinetics of CBDCA in children, Newell put forward a modification of the Calvert et al. formula: dose [mg] = AUC $(\mathrm{mg} / \mathrm{ml} / \mathrm{min}) \times[\mathrm{GFR}(\mathrm{ml} / \mathrm{min})+0.36 \times$ body mass $(\mathrm{kg})][59]$. Another equation proposed by Newell can be used to calculate the dose of CBDCA, but this requires measuring the isotopic GFR, which limits its clinical application [59]. In everyday oncological paediatric practice, other modifications of the Calvert formula have also been used [60-62]. The results of the study published by Thomas et al. provided evidence that the administration of a CBDCA dose estimated from GFR results in more stable drug exposure when compared to a dose of CBDCA estimated from BSA [63].

\section{Late nephrotoxicity of platinum derivatives}

The late nephrotoxicity related to the administration of platinum derivatives is not fully characterised. Skinner et al. published results of a prospective study on 63 children treated with platinum derivatives (27 CDDP, 24 CBDCA, 12 both drugs). They reviewed kidney function by measurements of GFR, serum calcium and magnesium concentrations and an estimation of the overall grade of nephrotoxicity at the moment of the termination of the antineoplastic therapy, 1 year and 10 years later. Over time, no significant changes in kidney function were observed in any of the analysed groups. After 10 years of observation, eGFR $<60 \mathrm{ml} / \mathrm{min} / 1.73 \mathrm{~m}^{2}$ was found in $11 \%$ of the patients, severe nephrotoxicity in $15 \%$ of cases and hypomagnesaemia requiring oral magnesium supplementation in $7 \%$ of patients treated with CDDP [54].

Assessment of the chemotherapy-related nephrotoxicity in a group of 651 paediatric patients treated for sarcoma was performed (median follow-up 2 years) in a large multicentre study carried out by the CWS group. The median cumulative doses of CDDP and CBDCA were $360 \mathrm{mg} / \mathrm{m}^{2}$ and $1500 \mathrm{mg} / \mathrm{m}^{2}$, respectively. The patients not treated with platinum derivatives were considered the control group. Most of the patients, including the control group, received IFO treatment. Kidney function was assessed by creatinine and magnesium serum concentration levels and eGFR value. None of the patients exhibited a reduction in eGFR. After termination of the antineoplastic therapy, hypomagnesaemia (defined as serum magnesium concentration $<0.7$ $\mathrm{mmol} / \mathrm{l}$ ) was found in $12.1 \%$ of patients treated with CDDP and in $15.6 \%$ of patients receiving CBDCA, vs. $4.5 \%$ of patients from the control group ( $p=0.008)$. In all the groups, the incidence of hypomagnesaemia decreased with observation time, though the values of serum magnesium concentrations remained lower in patients treated with platinum derivatives throughout the study [55]. 


\section{Cancer combination therapy with nephrotoxic agents}

A combination therapy for cancer is correlated with the highest risk of nephrotoxicity. Combination of CDDP with IFO escalates kidney damage $[32,51,64]$. The prospective study of kidney function performed by Ferrari et al. on a group of 43 osteosarcoma patients receiving a combined therapy with IFO, CDDP and MTX showed that 21/43 patients had eGFR reduction. The combination therapy was further associated with glycosuria in 15/43 cases and proteinuria in 14/43 cases. Renal threshold TmP/GFR was $<1 \mathrm{mmol} / \mathrm{l}$ in 11 (52\%) patients [65].

\section{Nephrotoxicity of platinum derivatives in Wilms tumour patients}

Children diagnosed with Wilms tumour are predisposed to kidney filtration disturbances. Daw et al. published results of a prospective study of 12 patients diagnosed with highrisk Wilms tumour and treated with ICE chemotherapy, nephrectomy and radiotherapy. GFR reduction (measured by technetium 99 m-DTPA clearance) was found to be the key disorder present in those patients. Nephrectomy was the leading cause of GFR impairment (average 38\% reduction vs. $7 \%$ reduction after two cycles of ICE chemotherapy). Increased beta-microglobulin secretion without clinically overt dysfunction of the renal tubules was also present [66].

\section{Summary}

Kidney damage is a serious but rare side effect of anticancer treatment in children. Platinum derivatives are among the cytostatics with significant nephrotoxic potential. Cisplatin is the most nephrotoxic one. Cisplatin mainly reduces glomerular filtration rate and causes hypomagnesaemia. Evaluation of renal function is a very important diagnostic procedure during the active phase of the antineoplastic treatment as well as over the follow-up period. It allows early recognition of the therapy side effects. It should be noted that history of cancer constitues a risk factor of a chronic renal disease development.

\section{References}

1. Rossi R, Kleta R, Ehrich JHH. Renal involvement in children with malignancies. Pediatr Nephrol 1999; 13: 153-62.

2. Jones D, Spunt S, Green D, Springate J. Renal late effects in patients treated for cancer in childhood: a report from Children's Oncology Group. Pediatr Blood Cancer 2008; 51: 724-31.

3. Skinner R. Chronic ifosfamide nephrotoxicity in children. Med Pediatr Oncol 2003; 41: 190-7.

4. Pratt CB, Meyer WH, Jenkins JJ, Avery L, McKay CP, Wyatt RJ, Hancock ML. Ifosfamide, Fanconi's syndrome, and rickets. I Clin Oncol 1991; 9: 1495-9.

5. Loebstein R, Atanackovic G, Bishai R, et al. Risk factors for long-term outcome of ifosfamide-induced nephrotoxicity in children. J Clin Pharmacol 1999; 39: 454-61.

6. Arany I and Safirstein RL. Cisplatin nephrotoxicity. Semin Nephrol 2003; 23: 460-4.
7. Cummings BS, Schnellmann RG. Cisplatin-induced renal cell apoptosis: Caspase 3-dependent and - independent pathways. J Pharmacol Exp Ther 2002; 302: 8-17.

8. Hanigan M, Devarajan P. Cisplatin nephrotoxicity: molecular mechanisms. Cancer Ther 2003; 1: 47-61.

9. Ciarimboli G, Ludwig T, Lang D, et al. Cisplatin nephrotoxicity is critically mediated via the human organic cation transporter 2 . Am J Pathol 2005; 167: 1477-84

10. Townsened DM, Deng M, Zhang L, Lapus MG, Hanigan MH. Metabolism of cisplatin to a nephrotoxin in proximal tubule cells. J Am Soc Nephrol 2003; 14: 1-10

11. Finkel KW, Foringer JR. Renal disease in patients with cancer. Nat Clin Pract Nephrol 2007; 3: 669-78.

12. Pabla N, Dong Z. Cisplatin nephrotoxicity: Mechanisms and renoprotective strategies. Kidney Int 2008; 73: 994-1007.

13. Zhang B, Ramesh G, Norbury CC, Reeves WB. Cisplatin-induced nephrotoxicity is mediated by tumor necrosis factor-alpha produced by renal parenchymal cells. Kidney Int 2007; 72: 37-44.

14. Skinner R, Pearson ADJ, English MW, Price L, Wyllie RA, Coulthard MG, Craft AW. Cisplatin dose rate as a risk factor for nephrotoxicity in children. Br J Cancer 1998; 77: 1677-82.

15. Fujieda M, Matsunaga A, Hayashi A, Tauchi H, Chayama K, Sekine T. Children's toxicology from bench to bed - drug-induced renal injury. Nephrotoxicity induced by cisplatin and ifosfamide in children. Toxicol Sci 2009; 34: SP251-SP257.

16. Lajer H, Daugaard G. Cisplatin and hypomagnesemia. Cancer Treat Rev 1999; 25: 47-58.

17. Swainson CP, Colls BM, Fitzharris BM. Cis-platinum and distal renal tubule toxicity. New Zealand Med J 1985; 98: 375-78.

18. Mavichak V, Wong NL, Quamme GA, Magil AB, Sutton RA, Dirks JH. Studies on the pathogenesis of cisplatin-induced hypomagnesemia in rats. Kidney Int 1985; 28: 914-21.

19. Magil AB, Mavichak V, Wong NL, Quamme GA, Dirks JH, Sutton RA. Long-term morphological and biochemical observations in cisplatininduced hypomagnesemia in rats. Nephron 1986; 43: 223-30.

20. Goren M. Cisplatin nephrotoxicity affects magnesium and calcium metabolism. Med. Pediatr Oncol 2003; 41: 186-9.

21. Brock PR, Koliouskas DE, Barratt TM, Yeomans E, Pritchard J. Partia reversibility of cisplatin nephrotoxicity in children. J Pediatr 1991; 118: 531-34.

22. Bianchetti MG, Kanaka C, Ridolfi-Luthy A, Wagner HP, Hirt A, Paunier L, Peheim E, Oetliker OH. Chronic renal magnesium loss, hypocalciuria, and mild hypokalaemic metabolic alkalosis after cisplatin. Pediatr Nephrol 1990; 4: 219-22.

23. Bianchetti MG, Kanaka C, Ridolfi-Luthy A, Hirt A, Wagner HP, Oetliker $\mathrm{OH}$. Persisting renotubular sequelae after cisplatin in children and adolescents. Am J Nephrol 1991; 11: 127-30.

24. Ariceta G, Rodriguez-Soriano J, Vallo A, Navajas A. Acute and chronic effects of cisplatin therapy on renal magnesium homeostasis. Med Pediatr Oncol 1997; 28: 35-40.

25. Daugaard G, Abildgaard U. Cisplatin nephrotoxicity. Cancer Pharmacol 1989; 25: 1-9.

26. Cao L, Joshi P, Sumoza D. Renal salt-wasting syndrome in a patient with cisplatin-induced hyponatremia. Am J Clin Oncol 2002; 25: 344-6.

27. Vassal G, Rubie H, Kalifa C, Hartmann O, Lemerle J. Hyponatremia and renal sodium wasting in patients receiving cisplatinum. Ped Hem Oncol 1987; 4: 337-44.

28. Womer RB, Pritchard J, Baratt TM. Renal toxicity of cisplatin in children. J Pediatr 1985; 106: 659-63.

29. Erdlendbruch B, Nier M, Kern W, Hiddemann W, Pekrun A, Lakomek M. Pharmacokinetics of cisplatin and relation to nephrotoxicity in paediatric patients. Eur J Clin Pharmacol 2001; 57: 393-402.

30. De Santo NG, Capasso G, Capodicasa G, Tancredi F, Nuzzi F, Giordano G. Acute renal failure due to cisplatin. Int J Pediatr Nephrol 1986; 7: 145-50.

31. Pietilä S, Ala-Houhala M, Lenko H, Harmoinen A, Turjanmaa V, Mäkipernaa A. Renal impairment and hypertension in brain tumor patients treated in childhood are mainly associated with cisplatin treatment. Pediatr Blood Cancer 2005; 44: 363-9.

32. Hartmann JT, Fels LM, Knop S, Stolt H, Kanz L, Bokemeyer C. A randomized trial comparing the nephrotoxicity of cisplatin/ifosfamide- 
based combination chemotherapy with or without amifostine in patients with solid tumors. Invest New Drugs 2000; 18: 281-9.

33. Gomez Campdera FJ, Gonzalez P, Carrillo A, Estelles MC, Rengel M. Cisplatin nephrotoxicity: symptomatic hypomagnesemia and renal failure. Int J Pediatr Nephrol 1986; 7: 151-2.

34. Hayes DM, Cvitkovic E, Golbey RB, Scheiner E, Helson L, Krakof IH. High dose cis-platinum diammine dichloride: amelioration of renal toxicity by mannitol diuresis. Cancer 1977; 39: 1372-81.

35. Polycarpe E, Arnould L, Schmitt E, et al. Low urine osmollarity as a determinant of cisplatin-induced nephrotoxicity. Int I Cancer 2004; 111: 131-7.

36. Ozols RF, Corden BJ, Jacob J, Wesley MN, Ostchega Y, Young RC. High-dose cisplatinin hypertonic saline. Ann Intern Med 1984; 100: 19-24.

37. Kemp G, Rose P, Lurain J, et al. Amifostine pretreatment for protection against cyclophosphamide-induced and cis-platin induced toxicities: results of a randomized control trial in patients with advanced ovarian cancer. J Clin Oncol 1996; 14: 2101-12.

38. Fisher MJ, Lange BJ, Needle MN, Janss AJ, Shu HK, Adamson PC, Phillips PC. Amifostine for children with medulloblastoma treated with cisplatin-based chemotherapy. Pediatr Blood Cancer 2004; 43: 780-4.

39. Petrilli AS, Oliveira DT, Ginani VC, et al. Use of amifostine in the therapy of osteosarcoma in children and adolescents. J Pediat Hematol Oncol 2002; 24: 188-91.

40. Dickey DT, Muldoon LL, Doolittle ND, Peterson DR, Kraemer DF, Neuwelt EA. Effect of $\mathrm{N}$-acetylcysteine route of administration on chemoprotection against cisplatin-induced toxicity in rat models. Cancer Chemother Pharmacol 2008; 62: 235-41.

41. Dickey DT, Wu J, Muldoon LL, Neuwelt EA. Protection against cisplatin-induced toxicities by $\mathrm{N}$-acetylcysteine and sodium thiosulate as assessed at the molecular, cellular, and in vivo levels.J Pharmacol Exp Ther 2005; 314: 1052-58.

42. Sheikh-Hamad D, Timmins K, Jalali Z. Cisplatin-induced renal toxicity: possible reversal by $\mathrm{N}$-acetylcysteine treatment. J Am Soc Nephrol 1997; 8: 1640-45

43. Wu YJ, Muldoon LL, Neuwelt EA. The chemoprotective agent Nacetylcysteine blocks cisplatin-induced apoptosis through caspase signaling pathway. J Pharmacol Exp Ther 2005; 312: 424-31.

44. Rapkin L. Paracetamol and cisplatin with $n$-acetylcysteine rescue for recurrent, refractory hepatoblastoma and hepatocellular carcinoma: A Phase II SIOPEL Study 2009.

45. Bassinger MA, Jones MM, Holscher MA. L-methionine antagonism of cis-platinum nephrotoxicity. Toxicol Appl Pharmacol 1990; 103: 1-15.

46. Atasayar S, Gürer-Orhan H, Orhan H, Gürel B, Girgin G, Özgüne H. Preventive effect of aminoguanidine compared to vitamin $E$ and $C$ on cisplatin-induced nephrotoxicity in rats. Ex Toxicol Pathol 2009, 61: 23-32

47. Stathopoulos GP. Liposomal cisplatin: a new cisplatin formulation Anti-Cancer Drugs 2010; 21: 732-36.

48. Devarajan P, Tarabishi R, Mishra J, Ma Q, Kourvetaris A, Vougiouka M, Boulikas T. Low renal toxicity of lipoplatin compared to cisplatin in animals. Anticancer Res 2004; 24: 2193-200.

49. Yasumasu T, Ueda T, Uozumi J, Mihara Y, Kumazawa J. Comparative study of cisplatin and carboplatin on pharmacokinetics nephrotoxicity and effect on renal nuclear DNA synthesis in rats. Pharmacol toxicol 1992; 70: 143-7.

50. English MW, Skinner R, Pearson ADJ, Price L, Wyllie R, Craft AW. Dose-related nephrotoxicity of carboplatin in children. Br J Cancer 1999; 81: 336-41.

51. Marina NM, Poquette CA, Cain AM, Jones D, Pratt CB, Meyer WH. Comparative renal tubular toxicity of chemotherapy regimens includ ing ifosfamide in patients with newly diagnosed sarcomas. J Pediatr Hematol Oncol 2000; 22: 112-8.

52. Kintzel PE. Anticancer drug-induced kidney disorders. Drug Saf 2001; 24: 19-38.

53. Frenkel J, Kool G, de Kraker J. Acute renal failure in high dose carboplatin chemotherapy. Med Pediatr Oncol 1995; 25: 473-4.

54. Skinner R, Parry A, Price L, Cole M, Craft AW, Pearson ADJ. Persistent nephrotoxicity during 10-year follow-up after cisplatin or carboplatin treatment in childhood: relevance of age and dose as risk factors. Eur I Cancer 2009; 45: 3213-9.
55. Stöhr W, Paulides M, Bielack S, Jürgens H, Koscielniak E, Rossi R, Langer T, Beck JD. Nephrotoxicity of cisplatin and carboplatin in sarcoma patients: a report from the Late Effects Surveillance System. Pediatr Blood Cancer 2007; 48: 140-7.

56. Brandt LJ, Broadbent V. Nephrotoxicity following carboplatin use in children: is routine monitoring of renal function necessary? Med Pediatr Oncol 1993; 21: 31-5.

57. Bergeron C, Dubourg L, Chastagner P, et al. Long-term renal and hearing toxicity of carboplatin in infants treated for localized and unresectable neuroblastoma: results of the SFOP NBL90 Sudy. Pediatr Blood Cancer 2005; 45: 32-6.

58. Calvert AH, Newell DR, Gumbrell LA, et al. Carboplatin dosage: prospective evaluation of a simple formula based on renal function. J Clin Oncol 1989; 7: 1748-56.

59. Newell DR, Pearson ADJ, Balmanno K, et al. Carboplatin pharmacokinetics in children: the development of a pediatric dosage formula. J Clin Oncol 1993; 11: 2314-70.

60. Tonda ME, Heideman RL, Petros WP, Friedman HS, Murry DJ, Rodman JH. Carboplatin pharmacokinetics in young children with brain tumours. Cancer Chemother Pharmacol 1996; 38: 395-400.

61. Marina NM, Rodman JH, Sherma SJ, et al. Phase I study of escalated doses of carboplatin combined with ifosfamide and etoposide in children with relapsed solid tumors. I Clin Oncol 1993; 11: 554-60.

62. Marina NM, Rodman JH, Murry DJ, et al. Phase I study of escalating targeted doses of carboplatin combined with ifosfamide and etoposide in treatment of newly diagnosed pediatric solid tumours. Natl Cancer Inst 1994; 86: 544-8.

63. Thomas H, Boddy AV, English MW, et al. Prospective validation of renal function-based carboplatin dosing in children with cancer: a United Kingdom Children's Cancer Study Group Trial. J Clin Oncol 2000; 18: 3614-21.

64. Rossi R, Danzebrink S, Hillenbrand D, Linnenburger K, Ullrich K, Jürgens $\mathrm{H}$. Ifosfamide-induced subclinical nephrotoxicity and its potentiation by cisplatinum. Med Pediatr Oncol 1994; 22: 27-32.

65. Ferrari S, Pieretti F, Verri E, et al. Prospective evaluation of renal function in pediatric and adult patients treated with high-dose ifosfamide, cisplatin and HD MTX. Anticancer Drugs. 2005; 16: 733-8.

66. Daw NC, Gregornik D, Rodman J, et al. Renal function after ifosfamide, carboplatin and etoposide (ICE) chemotherapy, nephrectomy and radiotherapy in children with Wilms tumour. Eur J Cancer 2009; 45: 99-106.

\section{Address for correspondence}

\section{Joanna Stefanowicz}

Department of Paediatric, Haematology, Oncology and Endocrinology Medical University of Gdansk

Dębinki 7

80-952 Gdansk

e-mail: jstefanowicz@gumed.edu.pl

tel. +48583492880

$\mathrm{fax}+48583492847$ 